\title{
The Northeast India in the Midst of Climate Change
}

\section{Fahima Khanum}

Academy of International Studies, Jamia Millia Islamia University, New Delhi, India

"Corresponding author: khan.tia@gmail.com (ORCID ID: 0000-0001-5182-5852)

Paper No. 930

Received: $20-06-2021$

Revised: 28-08-2021

Accepted: 03-09-2021

\begin{abstract}
With increased temperatures, melting glaciers, decreasing water supplies- the threat of climate change is becoming very real. The IPCC report on climate change has warned that these effects will only worsen, especially for developing and tropical countries, if action is not taken now. The Northeast region of India is highly vulnerable because of its location, its transboundary river basins, and socio-economic instabilities. The threat of climate change has only heightened these vulnerabilities through flood, drought, heatwaves, soil erosion, loss of livelihood, and migration. Thus, challenging the very sustainability and security of the region. Every year, the northeast region is increasingly seeing fewer rainfalls, leading to a droughtlike situation in the states of Meghalaya, Tripura, Assam, Arunachal Pradesh Manipur, Mizoram. With the farmers relying on the monsoon, this lessening of waters adversely affects agriculture; for instance, rice production in Assam has fallen by 15-20\%. The majority of people in Assam rely on agriculture for their livelihood. Because of climate change and the lessening of agricultural production, the food prices in Assam are pushed up. In Assam, 35\% of the population lives below the poverty line. A rise in prices and loss of livelihood force the people to migrate in search of new opportunities and means of livelihood. Often women bear the brunt of this situation, with them having to take up labor as housemaids or, in a worse situation, pushed into flesh trade. The Intergovernmental Panel on Climate Change special report on 'Climate Change and Land' reports that about one third of the food that is produced is lost or wasted and by reducing this wastage we can reduce greenhouse gas emissions as well as improve food security. Thus, killing two birds with one stone.

\section{HIGHLIGHTS}

( Climate Change is leading to lower agricultural yield in the Northeast region and hence is affecting the food security of the area.

(0 It is also leading to decreased incomes, loss of livelihoods and is forcing people to migrate in search of better opportunities.

(0 There are increased incidents of vector borne diseases as a result of climate change.

o Climate change has a direct negative impact on Women.
\end{abstract}

Keywords: Climate change, Northeast India, food security, migration

The world we see today is becoming increasingly indefinite, with changing climatic conditions, weather patterns, increasing temperatures, rainfall, and precipitation variability. Climate change is at the root of these variabilities, having a negative impact on the health, food, livelihood and security of the people. These vulnerabilities are further enhanced for developing countries like India, where people are highly dependent on climate sensitive sectors and do not have the resilience- necessary resources and the adaptive skills to cope with the challenge of climate change. Vulnerability to climate change is the degree to which geophysical, biological and socio-economic systems are susceptible to and unable to cope with the adverse impacts of climate change whereas, resilience is the degree to

How to cite this article: Khanum, F. 2021. The Northeast India in the Midst of Climate Change. IJAEB, 14(03): 447-452.

Source of Support: None; Conflict of Interest: None (ब) 9 
which geophysical, biological and socio-economic systems rebound, recoup or recovers from adverse effects of climate change (AR 4, 2007). India is highly dependent on the environment for food and livelihood, which makes Indians highly susceptible to climate change. The impact of climate change and its associated costs will fall disproportionately on the developing countries threatening to undermine the achievement of the Sustainable Development Goals of No Poverty and Zero Hunger, as climate change will reduce access to drinking water, affect the health of the people, especially the poor and pose a threat to food security. According to the IPCC Report, "Climate-related risks to health, livelihoods, food security, water supply, human security, and economic growth are projected to increase with global warming of $1.5^{\circ} \mathrm{C}$ and increase further with $2^{\circ} \mathrm{C} . "$ (IPCC, 2018). These effects are more likely to be felt by disadvantaged and vulnerable populations, indigenous people, and local communities dependent on agricultural or coastal livelihoods. The poor are more vulnerable as their capacity to adapt is low due to limited choices and opportunities, the small land holdings, and lack of access to markets.

\section{ACTOR LANDSCAPE}

The North-East region of India consists of eight States- Arunachal Pradesh, Assam, Manipur, Meghalaya, Mizoram, Nagaland, Sikkim, and Tripura. This region is a biological diversity hotspot, accounting for more than one-third of the country's total biodiversity and nearly $25 \%$ of the total forest cover. The northeast region is riddled with problems of its own, like- hilly terrain, poor infrastructure, fragmented land holdings, jhum cultivation, extensive deforestation, land degradation- and climate change adds to it. It is highly vulnerable to climate change as $82 \%$ of its people live in rural areas, depending on natural resources for food and livelihood (IPCC, 2019).

Hence, agriculture plays a vital role in determining the economy of the region. The people depend on the southwest monsoon to fulfill their agricultural water requirements, putting their survival at the mercy of climate change. In recent years, the northeast region has been subject to several climateinduced risks that adversely affect natural resources. The Brahmaputra river creates mayhem by causing floods, and climate change will only exacerbate it further.

On the other hand, deficit rainfall has also caused droughts in the region, especially in Assam. Apart from extreme events, changes in the trends of the meteorological parameters are likely to impact the natural resources and the livelihoods of the dependent communities. Climate change impacts different sectors differently, which will be studied below.

\section{Forests}

The northeast region has about 143,360 sq. $\mathrm{km}$ of forests which cover around $61 \%$ of the total land area, the highest for India. Much of the dense forests of Arunachal Pradesh, Assam, and Nagaland are part of the Himalayan biodiversity hotspot. However, the quality of the natural landscape has been highly degraded due to pressure on land from small jhum cultivation, exploitation of forests for timber, and no proper scientific management strategy. Modeling studies using IBIS (MoEFCC, 2010) projected the impacts of climate change on forests for the short to midterm (2021-2050). It was deduced that forests in the northern part of the northeast were primarily impacted by climate change, leading to the extreme vulnerability of the Himalayan biodiversity hotspots. Net primary productivity was projected to increase by $23 \%$ in the region, followed by increased soil carbon and biomass, leading to changes in vegetation type. The percentage of people dependent on forests for their food and livelihood needs is quite high in the northeast. This is leading to a deterioration of land cover due to jhum cultivation and deforestation, making the land unfit for future use.

\section{Agriculture}

In the northeast the pattern of agricultural growth is uneven across the region, with food production being highly subjective and dependent on climatic variabilities. The problem of climate change puts additional stress and has direct consequences on the food systems and food security of the region. Agriculture faces acute climate -related threats. If the agriculture potential is reduced, the socio-economic impacts would be severe as agriculture is both a source of livelihood and food for people of the region. It provides the people with food to eat and 
Table 1: Agricultural Vulnerability Ranking of Districts (Ravindranath, 2019)

\begin{tabular}{|c|c|c|c|c|c|c|c|c|c|c|c|}
\hline \multicolumn{6}{|c|}{ Least Vulnerable } & \multicolumn{6}{|c|}{ Most Vulnerable } \\
\hline \multicolumn{3}{|c|}{ Current } & \multicolumn{3}{|c|}{$2030 s$} & \multicolumn{3}{|c|}{ Current } & \multicolumn{3}{|c|}{$2030 s$} \\
\hline State & District & Ranking & State & District & Ranking & State & District & Ranking & State & District & Ranking \\
\hline Manipur & Tamenglong & $2 / 78$ & Manipur & Tamenglong & $2 / 78$ & Meghalaya & $\begin{array}{l}\text { South } \\
\text { Garo Hills }\end{array}$ & $68 / 78$ & Meghalaya & $\begin{array}{l}\text { South } \\
\text { Garo Hills }\end{array}$ & $68 / 78$ \\
\hline Tripura & $\begin{array}{l}\text { South } \\
\text { Tripura }\end{array}$ & $4 / 78$ & Tripura & $\begin{array}{l}\text { South } \\
\text { Tripura }\end{array}$ & $4 / 78$ & Manipur & Bisnupur & $70 / 78$ & Manipur & Bisnupur & $70 / 78$ \\
\hline Arunachal & East Siang & $5 / 78$ & Arunachal & Papumpare & $5 / 78$ & Mizoram & Saiha & $71 / 78$ & Mizoram & Saiha & $71 / 78$ \\
\hline Sikkim & $\begin{array}{l}\text { North } \\
\text { Sikkim }\end{array}$ & $6 / 78$ & Sikkim & $\begin{array}{l}\text { North } \\
\text { Sikkim }\end{array}$ & $6 / 78$ & Tripura & $\begin{array}{l}\text { West } \\
\text { Tripura }\end{array}$ & $72 / 78$ & Tripura & $\begin{array}{l}\text { West } \\
\text { Tripura }\end{array}$ & $72 / 78$ \\
\hline Nagaland & Dimapur & $7 / 78$ & Nagaland & Dimapur & $7 / 78$ & Arunachal & Tirap & $73 / 78$ & Arunachal & $\begin{array}{l}\text { Dibang } \\
\text { Valley }\end{array}$ & $73 / 78$ \\
\hline Tripura & $\begin{array}{l}\text { North } \\
\text { Tripura }\end{array}$ & $9 / 78$ & Arunachal & $\begin{array}{l}\text { Upper } \\
\text { Subansiri }\end{array}$ & $9 / 78$ & Nagaland & Tuensang & $75 / 78$ & Nagaland & Tuensang & $75 / 78$ \\
\hline Manipur & Ukhrul & $10 / 78$ & Manipur & Ukhrul & $10 / 78$ & Meghalaya & $\begin{array}{l}\text { East Garo } \\
\text { Hills }\end{array}$ & $76 / 78$ & Meghalaya & $\begin{array}{l}\text { East Garo } \\
\text { Hills }\end{array}$ & $76 / 78$ \\
\hline
\end{tabular}

sell to earn their livelihood. An estimated 3.5 million hectares of area is under rainfed rice cultivation, accounting for about $30 \%$ of the total area under cultivation in the region. Model simulations using INFOCROP a dynamic crop model, for rice in 64 districts of the North East showed that the yield will undergo a change in most districts in the future under the A1B scenario, with an increase in yield projected for 21 districts and a decrease in yield for 43 districts (up to $10 \%$ ); highest decrease in yield was observed for North Sikkim District of Sikkim (Aggrawal et al. 2016).

The northeast region sees higher agricultural vulnerability in the north, which keeps on declining towards the south. Since agricultural vulnerability is a function of crop production and input (fertilizer, irrigation), the higher vulnerability may be lower input levels. The high relative variability of rainfall, floods, and droughts leads to lower agricultural yield and food insecurity. There is ing evidence that climate change is endangering the tea plantations in Assam and leading to decreased tea yields in the region.

\section{Water}

The North East region possesses an enormous water resource potential which is 34 percent of India's total water resource (Sharma et al. 2010). Although this region has the highest per capita and hectare water availability in India, only $5 \%$ of the water potential is realized. Although the groundwater is available at a shallow depth of within 20 meters. 3 percent of the existing groundwater resource has been developed (Mahanta 2006). This is because most of the region is made up of hard crystalline granites, granulites, and gneisses that block rainwater infiltration for groundwater recharge. When the region already suffers from water scarcity, climate change will only intensify it further and make the community more vulnerable. The water resources in the northeast region face many challenges in the form of- increased demand for water due to population growth, economic development, unplanned urbanization, unsustainable land use, especially in the upper reaches, which leads to excess surface water runoff and depletion of the topsoil, poor management of water structure etc.

Climate change adds to this challenge through rivers running dry, changes in rainfall patterns, vanishing springs. This is also making communities to abandon their livelihood options that are heavily dependent on water. Climate change and deforestation lead to the vanishing of many springs and creating severe problems in States like Manipur, where spring is the primary source of water. Warmer climate leads to uncontrolled growth of weeds in the lakes that 
pollute water. Increasing phoomdis in Loktak Lake may be related to climate change (Singh and Dhar 2017). Majuli, the world's largest riverine island, rainwater is a significant source of irrigation, and a minimal number of households depend on the use of water pumps. Due to decreased rains, floods resulting from climate change, the agricultural output has decreased. This has led to a decrease in agricultural income, and people with already limited income strongly feel this decreased income. In past 10 years, nearly $30 \%$ of households have lost their source of livelihood and are forced to migrate to cities. Majuli is highly vulnerable to climate change as it experiences frequent floods and has a severe problem of vector-borne diseases. With a high poverty rate of $21.47 \%$, the climate crisis further pushes people towards poverty as they lose their livelihood to climate extremes.

\section{Health}

The northeast region is highly susceptible to vector-borne diseases, which are a major public health concern. Increased flooding incidents in the region have led to the spread of Japanese Encephalitis, malaria, dengue and lymphatic filariasis. High temperatures, humidity, paddy cultivation create conditions conducive for the spread of these diseases. Among these diseases, malaria and Japanese encephalitis are predominant and spread to Assam, Mizoram, Arunachal Pradesh. In overall, India, Meghalaya, Mizoram, Tripura, and Arunachal Pradesh had the highest deaths per 100,000 population due to malaria between 2013 and September 2017.

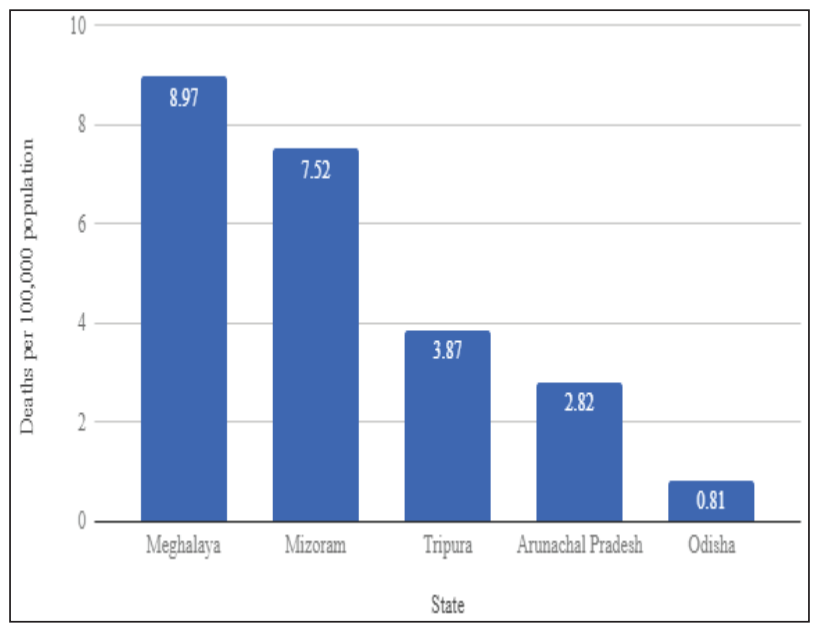

Fig. 1: States by Malaria Death rate 2013-2017 (Vipul, 2017)

\section{Migration}

Climate change is one of the growing reasons of migration across the world. IPCC in its first assessment report had mentioned that by 2050, approximately 150 million people could be displaced due to climate-induced factors like droughts, floods, and storms. Recent studies show that climate change has lead to the migration of rural communities to cities or other states in search of better livelihood opportunities. Climate change will lead to increased migration due to factors like drying up of some regions, decreasing agricultural production, and high precipitation leading to floods inlow-lying areas. Rural communities dependent on agriculture will be forced to migrate in search of new livelihood options. Large numbers of people are displaced every year due to floods and droughts in most of the developing countries in Asia, and it is likely to increase in the coming years (ADB, 2012). High poverty rates, population growth, limited landholding size, limited livelihood opportunities, and government policies combined with environmental factors have increased forced migration in the global south. According to a report published by International Organization for Migration (IOM), forced migration increases pressure on urban infrastructure and services, undermines economic growth, increases the risk of conflict, thereby leading to low human development among the migrants (Brown 2011). Migration due to climate change is likely to evolve into a global crisis (Panda 2015). It leads to tensions in the migrant place where the native people are forced to compete with an increased labor force, ethnic tensions etc. For example, in Assam, people coming from central India and Bihar has caused ethnic tensions and violence in the past.

\section{Women and Climate Change}

Women are the worst affected by climate change and bear the brunt of it. Financial stress due to crop failure and the resulting decrease in incomes push women to find work elsewhere, which leaves them open to be preyed upon. Women are forced to work as domestic workers or worse, pushed into flesh trade. The economic vulnerabilities makes them victims of sexual abuse and exploitation. Young girls from the northeast are lured by promises of jobs and are instead sold into sex trafficking. 
According to a United Nations report on women and climate change, "Women are more vulnerable to the effects of climate change than men- primarily as they constitute the majority of the world's poor and are more dependent for their livelihood on natural resources that are threatened by climate change." In India, women constitute $65 \%$ of the agricultural workforce and $70 \%$ of the water-related chores globally. The burden of collecting water for agricultural and household purposes falls on the women. As groundwater disappears, women often have to walk long distances in scorching heat to collect it, resulting in extreme fatigue. Climate change also causes malnourishment and food insecurity amongst the people. It is generally seen that women of lower socioeconomic status have higher rates of anemia.

A resolution adopted at the $4^{\text {th }}$ Session of the UN Environment Assembly in Nairobi in March 2019 acknowledged the disproportionate burden of climate change on girls and women, it emphasized the power of their knowledge and collective action and the need to encourage women's participation and leadership in environmental-decision makingfrom the local to the international level. It also stressed the need to support training and -building efforts on gender mainstreaming and ensure meaningful participation in global processes.

\section{Adaptation to Climate Change}

Climate change adaptation in the northeastern region is not an end in itself but is a part of a broader sustainable development concept within the States and the northeast, integrating sustainable natural resource management, environmental protection, and socially inclusive growth. We cannot stop climate change and slow it down, but we can adapt to it. It is essential to adapt livelihood patterns so that the shock of climate change is minimized. The capabilities of the people must be enhanced so that they can deal with climate change in the best way.

At the global level, India's North East Climate Change Adaptation Program is one of the first to scientifically assess climate change's likely impact and use the said assessment as a base for supporting adaptation activities at the local level. It aims to strengthen the adaptive capacity of the local communities and reduce their vulnerability to climate change in a target-oriented manner.
Climate Change Adaptation in the North Eastern Region program is a bilateral program between the Government of India and the Federal Government of Germany, being implemented in the three states of Meghalaya, Nagaland and Sikkim in the NorthEastern Region of India. It aims to strengthen the adaptive capacity of people and organizations so as to enable them to cope with the consequences of climate change. It addresses the various issues of water, forests, fisheries, biodiversity, horticulture, urban and rural habitats, livelihoods, promotion of energy efficiency etc. The Government of Meghalaya and CCA-NER have set up a regional Centre for Adaptation to Climate Change in Shillong to improve data collection, management, and dissemination of informed decision making. This will aid in sharing relevant information with target groups like villagers, district councils, government institutions, and planning authorities. CACC acts as a convergence platform where data from other primary sources is compiled into one place. It serves as a discussion platform, facilitating learning and the exchange of ideas.

\section{CONCLUSION}

The perils of climate change are many, and if we do not act now, then it might be too late. So, the need of the hour is to educate the people about climate change, mitigation, and adaptation options, provide them with the necessary skills and induce them to practice sustainable farming practices. The knowledge and skills of people should be developed to combat climate change. They should be made aware of the dangers of climate change and educated in adaptation and mitigation methods. The government and NGOs should come together to educate people about the perils of jhum cultivation and make them practice more sustainable agricultural options. Villagers and the indigenous people who are the sentinels of forests should be included in the policy processtheir problems sold be talked about, and alternate forms of livelihood must be provided to them. So, the approach to climate change mitigation and disaster risk reduction should be centered around indigenous knowledge through the engagement of local communities and NGOs to promote sustainable livelihood options. 
ancen

\section{REFERENCES}

Aggarwal, P.K. et. al. 2006. InfoCrop: a dynamic simulation model for the assessment of crop yields, losses due to pests, and environmental impact of agro-ecosystems in tropical environments. Agric. Syst., 89: 47-67.

Asian Development Bank. 2012. Annual Report.

Brown, O. 2011. Migration and Climate Change. International Organization for Migration: Geneva.

IPCC, 2006. Fourth Assessment Report.

IPCC, 2018. Global Warming of $1.5^{\circ} \mathrm{C}$.

Mahanta, C. 2006. Water Resources of the Northeast: State of the Knowledge Base. Background Paper No. 2: 1-25.

Ministry of Environment Forests and Climate Change, GOI (2010) Climate Change and India: A $4 \times 4$ Assessment.

Panda, A. 2015. Climate Induced Migration from Bangladesh to India: Issues and Challenges. http://ssrn.com/ abstract=2186397. Accessed 12 March 2021.
Ravindranath, N.H. 2020. Climate Change and North East India. www.icimod.org resource Accessed $14^{\text {th }}$ October 2020.

Sharma, B.R., Riaz, M.V., Pant, D., Adhikary, D.L., Bhatt, B.P. and Rahman, H. 2010. Water poverty in the northeastern hill region (India): Potential Alleviation through multipleuse water systems: cross-learnings from Nepal Hills. IWMI., 1: 3.

Singh, S. and Dhar, I. 2017. Floods in Imphal Valley-Causes, Effects and Preventive Measures. Int. J. Eng. Technol. Manag. Appl. Sci., 5: 7-11.

Vipul, V. 2017. 4 Northeastern States Have Highest Death Rates Due To Malaria. https://www.factchecker.in/4northeastern-states-have-highest-death-rates-due-tomalaria/ Accessed 12 January 2021. 